Pediat. Res. 2: 451-455 (1968)

Cortisone RNA

DNA thymus

growth

\title{
Cortisone-Induced Growth Failure in Neonatal Rats
}

\author{
Myron Winick ${ }^{[12]}$ and Anthony Coscia \\ New York Hospital-Cornell Medical Center, New York, New York, USA
}

\begin{abstract}
Extract
Growth failure in two-day-old rats following a single injection of cortisone has been ascribed to thymic destruction. Specific early degeneration of thymus gland, however, has not been demonstrated. Moreover, the cellular changes in other organs accompanying this induced growth failure are unknown. Within 33 hours of injection of cortisone there is marked destruction of thymic and splenic cells, as indicated by a 50 -fold reduction in DNA content of these organs. On about the third day following injection, DNA, RNA, and protein content were proportionally reduced in seven other organs studied, and protein:DNA and RNA:DNA ratios remained normal. All organs, therefore, contained fewer cells of normal size. By three weeks of age, the thymus and the spleen were partially regenerated and showed reductions in DNA, RNA, and protein content in proportion to the amount present in other organs. These data demonstrate that the initial event after injection of $1 \mathrm{mg}$ of cortisone in two-day-old rats is the destruction of thymic and splenic cells. This is followed by partial regeneration of these organs. Later, cell division is slowed in other organs, resulting in a stunted animal whose organs contain fewer cells of normal size.
\end{abstract}

\section{Speculation}

Injection of a large dose of steroids into young animals will result in selective destruction of lymphoid tissue, subsequent immunologic tolerance, and growth failure. The stunted animal shows a continually reduced number of cells in certain organs. These data reinforce the concept that growth failure after steroid injection is secondary to massive destruction of lymphoid tissue and further support the hypothesis that the thymus may play a role in the regulation of growth during the neonatal period.

\section{Introduction}

Surgical removal of the thymus in very young rats results in a specific runting syndrome characterized by growth retardation, lymphoid hypoplasia and immunologic incompetence [5]. Similar changes can be produced by a single massive dose of cortisone $[1,2,6,7]$. Cortisone itself, however, has a direct effect on many tissues; therefore, the steroid-induced runting syndrome may be either secondary to thymic destruction or caused by direct tissue effects. SHapiro [6] was unable to demonstrate any increased destruction of thymus gland in animals studied two weeks after injection.

In order to separate primary from secondary effects of cortisone, animals were serially sacrificed after a single dose of cortisone injected on the second day of 
life. Total body weight and specific organ weight, DNA, RNA, and protein content were measured. Total organ DNA was considered to reflect cell number, whereas weight:DNA and protein:DNA were used as a reflection of cell size.

\section{Materials and Methods}

Pregnant Sprague Dawley rats were individually caged and fed a standard rat diet ad libitum. On the second day after delivery, one-half of each litter was given $1 \mathrm{mg}$ cortisone acetate in a $0.1 \mathrm{ml}$ solution by subcutaneous injection over the back. They were then marked and returned to their original litters; their littermates served as controls. On this dosage, all animals developed a typical runting syndrome [8] but survived to the conclusion of the experiment. One group of animals was weighed daily until the experiment was terminated. At specified times, a second group was killed by ether inhalation, transferred to a cold room and weighed. Organs were immediately dissected, weighed, homogenized to a $20 \%$ aqueous suspension, and then analyzed for DNA, RNA, and protein content according to methods previously described $[9,10]$. Because of the number of determinations performed, data have been expressed as percent of normal. Normal values for the rat organs at various ages in this study agree closely with previously reported normal values [9]. Actual values for experimental organs, therefore, can be calculated using the percentages given.
Results

\section{Total Body Weight}

A slight reduction in the weight of experimental animals could already be noted 33 hours after injection (fig. 1). This reduction increased progressively with time, so that at weaning (21 days), the weight of the

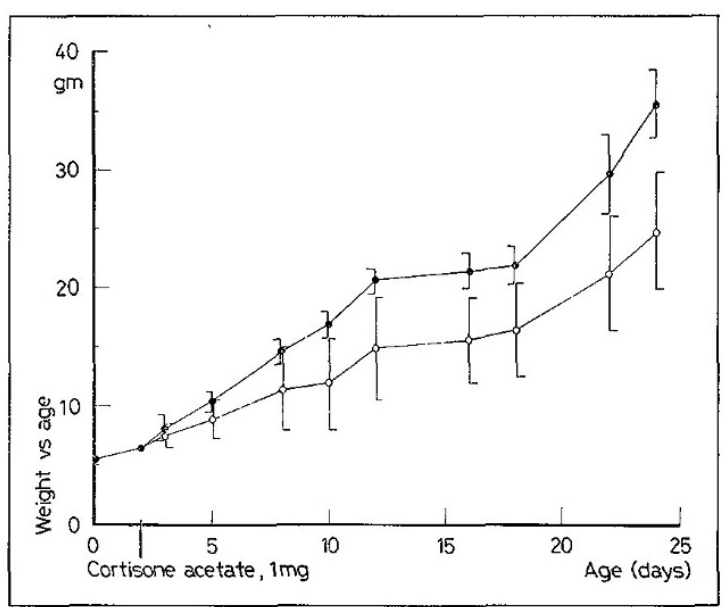

Fig.1. - Control; 0 injected. Each point represents the average of at least five animals. ] indicates range.

Fig. 2. Each point represents a single animal.

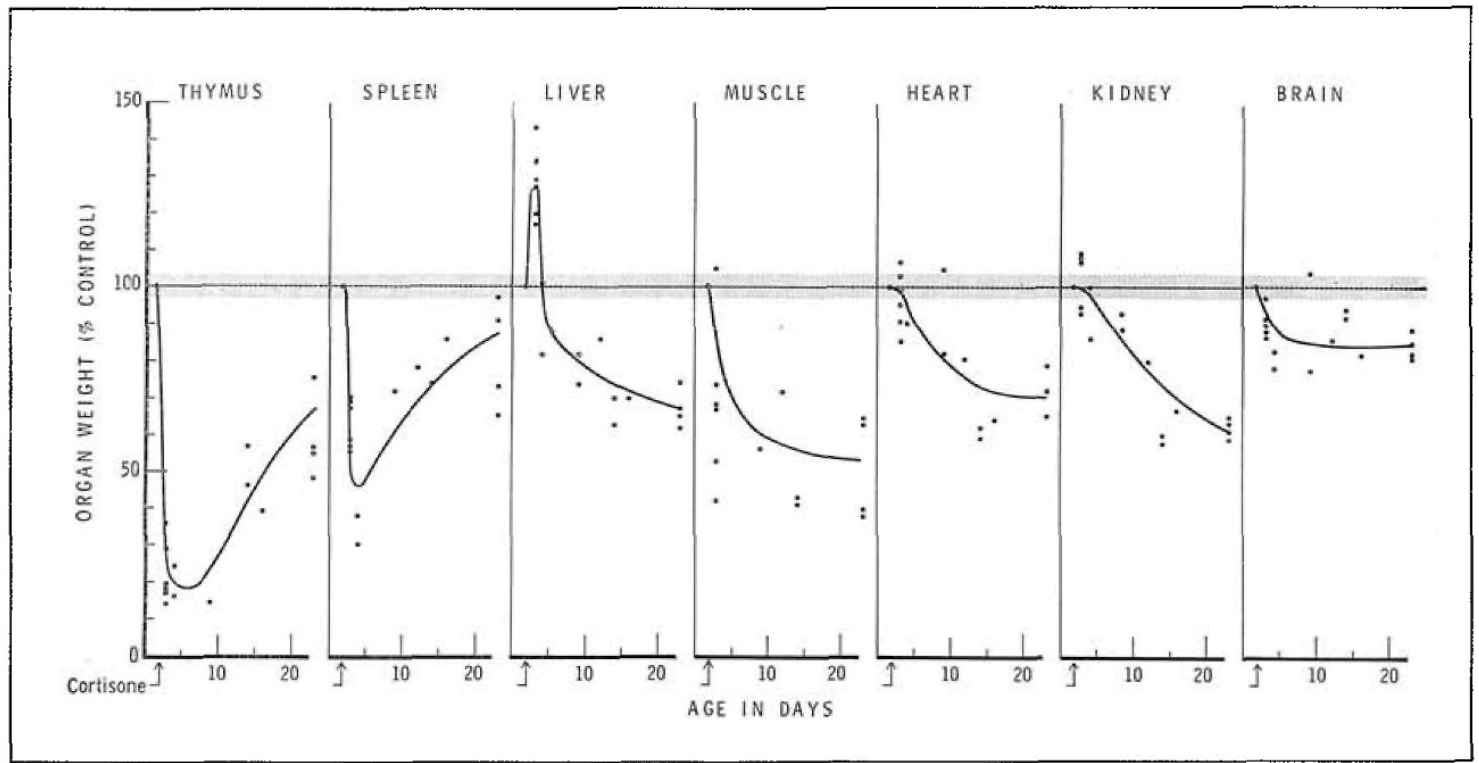


experimental animals was approximately $75 \%$ of that of the controls.

\section{Organ Weight}

Thirty-three hours after injection, weight of the thymus and the spleen was markedly reduced, skeletal muscle and brain weight were moderately reduced, whereas that of the kidney and the heart was unaffected (fig. 2). Liver actually increased in weight. By 48 hours, weight of all organs was significantly reduced. This weight loss increased progressively in all organs except lymphoid tissues. The initial rapid decline in weight of the thymus and the spleen was followed by partial recovery.

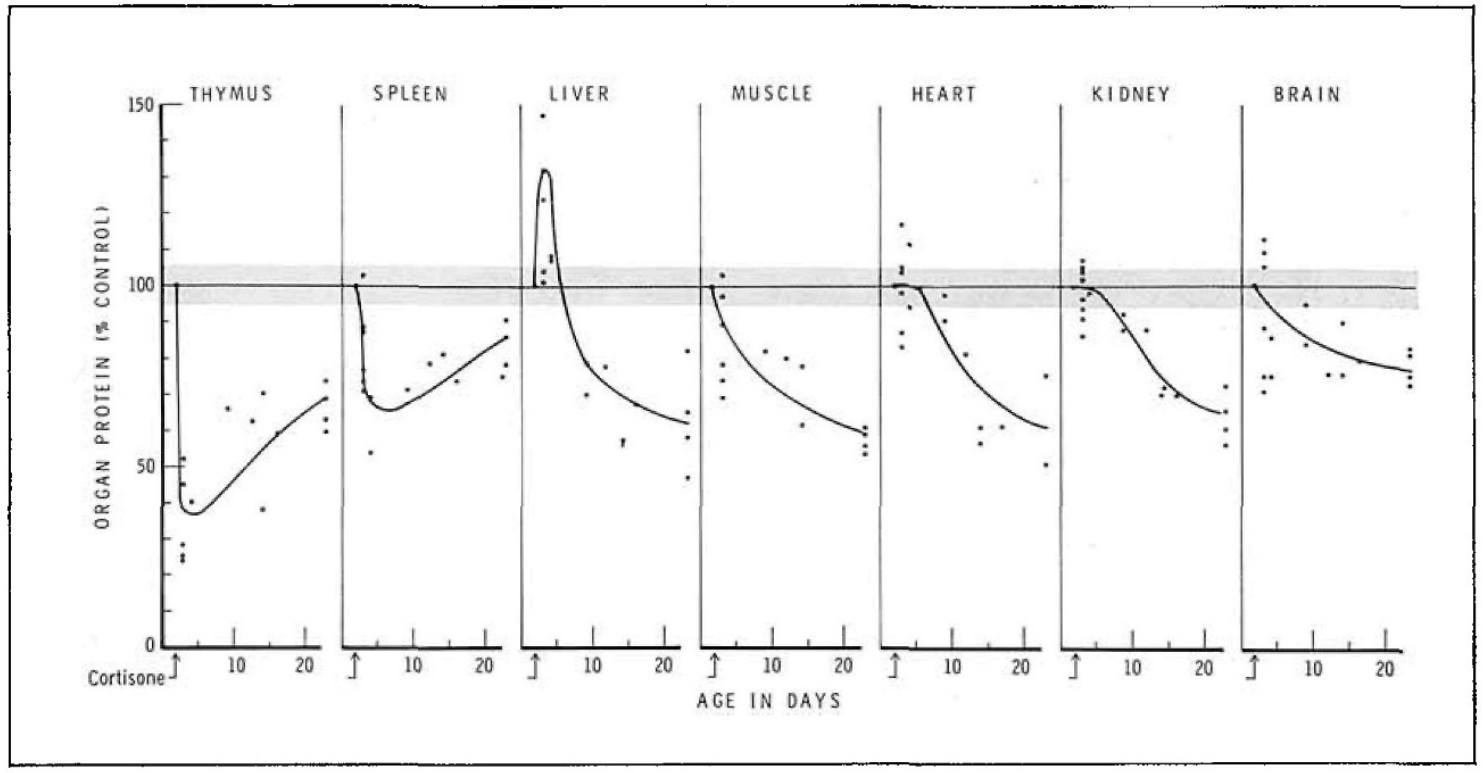

Fig. 3. Each point represents a single animal. Determinations were performed in triplicate with less than $1 \%$ difference between matched samples.

Fig.4. Each point represents a single animal. Determinations were performed in triplicate with less than $1 \%$ difference between matched samples.

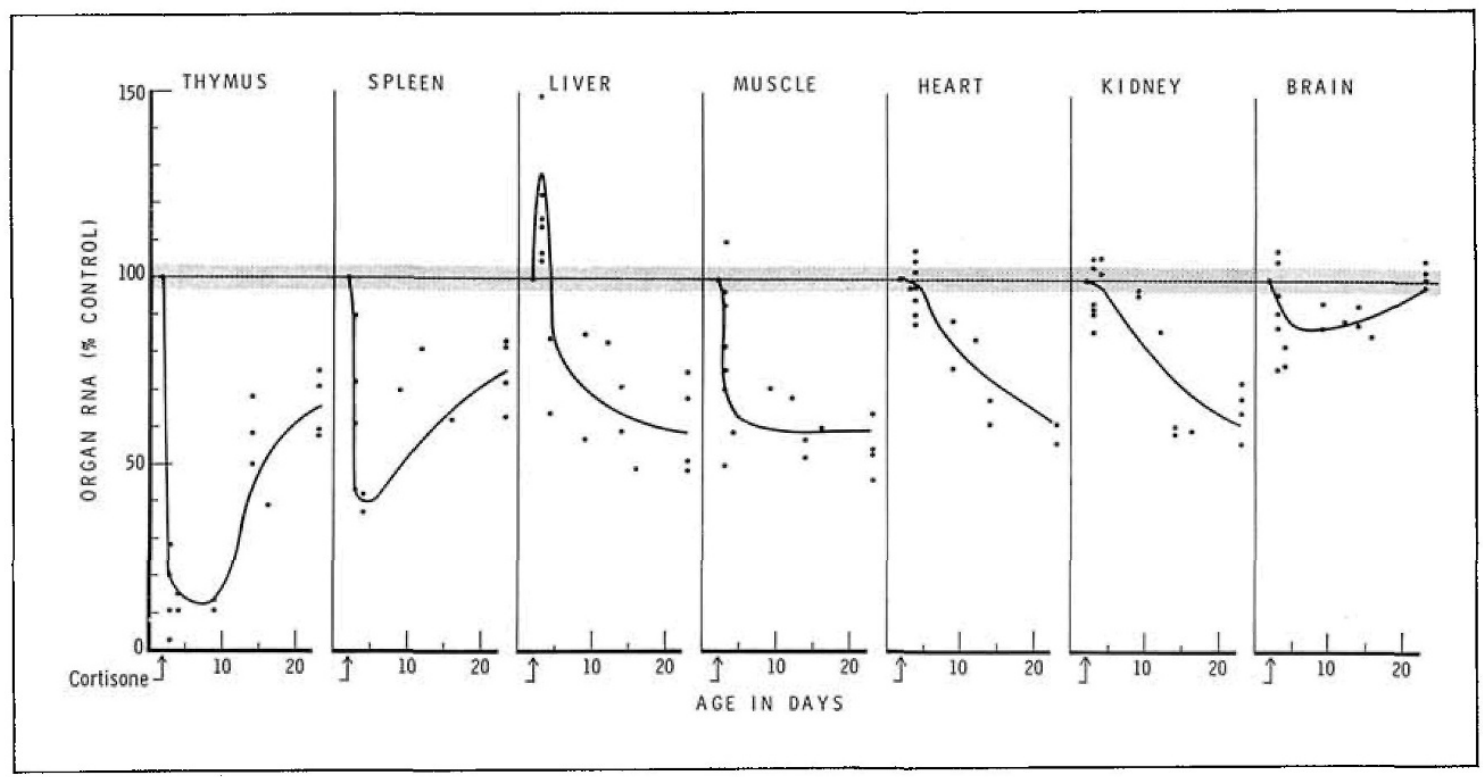

31 Pediat. Res., Vol. 2, No. 6 (1968) 


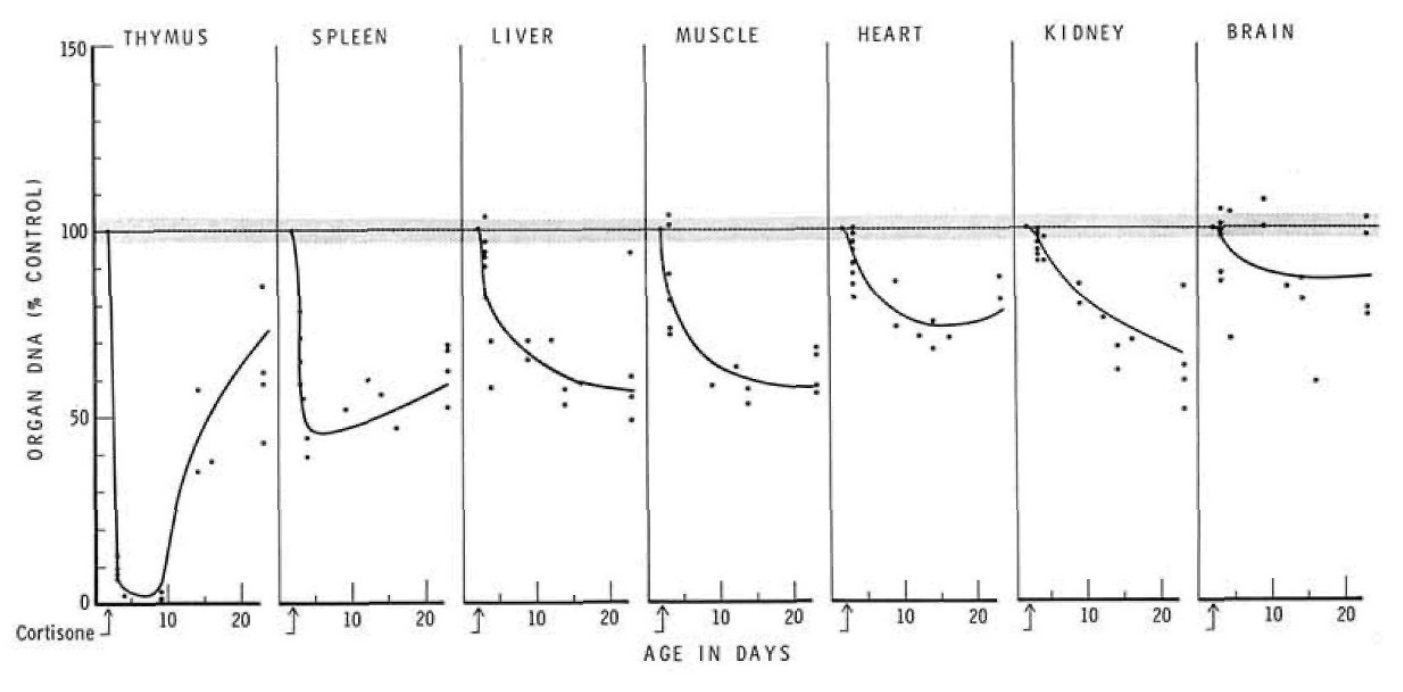

Fig. 5. Each point represents a single animal. Determinations were performed in triplicate with less than $1 \%$ difference between matched samples.

\section{Protein}

Changes in total organ protein generally paralleled the changes seen in organ weight (fig. 3). There were certain differences, however. At 33 hours after injection, the effect on protein content of the spleen was not as great; at 48 hours, liver protein was still increased. After 48 hours, the sequence was identical to that observed for total organ weight; i.e., there was partial recovery in the thymus and the spleen and increasing protein loss in all other organs.

\section{$R \mathcal{N} A$}

Changes in RNA content were also similar to those noted for weight (fig. 4). The same initial organ effects, as well as the same subsequent pattern, can be seen. There was one exception; the brain regained normal RNA content by 21 days.

\section{$D \mathcal{N A}$}

By 33 hours, DNA content of all organs was reduced. This reduction was marked in lymphoid tissue, whereas it was very small $(<10 \%)$ in all other organs. By 48 hours, DNA content was significantly reduced in all organs but, again, the reduction in lymphoid tissue was much greater than that observed in the other organs. DNA content continued to decrease in the nonlymphoid organs, whereas in the lymphoid tissue, partial recovery occurred.

\section{Discussion}

The thymus gland was severely affected as soon as 33 hours after a single injection of cortisone. By 48 hours, the number of cells (total DNA content) was reduced to $2 \%$ of normal. A similar but somewhat less marked effect occurred in the spleen. In contrast, DNA content of nonlymphoid tissues was only slightly reduced within the first 33 hours. Variable changes occurred in weight, protein, and RNA content. In the liver, these increased initially, but DNA content was reduced. This resulted in increases in the ratios weight: DNA, protein:DNA, and RNA: DNA. These changes agree with other observations on the effects of cortisone on the liver [3, 4]. Skeletal muscle and brain also showed weight reduction by 33 hours, and DNA content was reduced more in skeletal muscle than in the other nonlymphoid organs. The increase in the RNA: DNA ratio seen in the brain is also consistent with previously described results [3]. The mechanism for this increase in RNA content per cell is unknown.

Although these data suggest a direct destructive effect of cortisone on most tissues, marked destruction occurred only in lymphoid tissue. The major reduction in cell number observed in other tissues occurred after the thymus had been destroyed. Since the thymus regenerates rapidly, differential destruction is no longer visible by three weeks of age. At this time, the ratio of thymic weight or DNA content to body weight has returned to normal. During the recovery phase, the protein:DNA ratio in the spleen increases. This increase in 'cell size' is consistent with repopulation by less mature large cells as described by FACHET [2]. 
The exact mechanism for the lack of growth following either surgical or 'medical' thymectomy is unknown. We can conclude from these experiments, however, that although direct effects of cortisone could be demonstrated in most tissues, the major growth failure in these animals occurred after massive destruction of lymphoid tissue, most notably thymus. The stunted animals contained fewer cells in all organs and did not recover by three weeks of age.

\section{Summary}

Injection of $1 \mathrm{mg}$ of cortisone acetate into two-day-old rats resulted in a rapid and massive destruction of thymocytes and splenocytes. Growth retardation ensued. This retardation was accompanied by a reduction in the number of cells in the various organs studied. The thymus and the spleen regenerated and, by three weeks, exhibited a reduction in cell number proportional to the reduction in other organs.

\section{References and Notes}

1. Branceni, D. and Arnason, B.G.: Thymic involution and recovery: Immune responsiveness and immunoglobulins after neonatal prednisolone in rats. Immunology, Lond. 10: 35 (1966).

2. Fachet, J.; Palkovits, M.; Vallent, K. and STark, E.: Effect of a single glyco-corticoid injection on the first day of life in rats. Acta endocrin., Kbh. 51: 71-76 (1966).

3. HowARD, E.: Effects of corticosterone and food restriction on growth and on DNA, RNA and cholesterol contents of the brain and liver in infant mice. J. Neurochem. 12: 181 (1965).

4. LOWE, C. U. and RAND, R.N.: Effect of cortisone on DNA content of rat hepatocytes. J. biophys. biochem. Cytol. 2: 711 (1956).

5. MilleR, I.F.: Thymectomy in newborn rats. Retarded body development, hypoplasia, lymphoid system, and immunologic incompetence. Proc. roy. Soc. B. 156: 415 (1962).

6. Schapiro, S.: Neonatal cortisol administration: Effect on growth, the adrenal gland, and pituitaryadrenal response to stress. Proc. Soc. exp.Biol., N.Y. 120: 771-774 (1965).

7. Schapiro, S. and Huppert, M.: Neonatal cortisol administration and immunological impairment in the adult rat. Proc. Soc. exp. Biol., N.Y. 124: 744 (1967).

8. Schlesinger, M. and MArk, R.: Wasting disease induced in young mice by administration of cortisol acetate. Science 143: 965 (1964).

9. Winick. M. and Noble, A.: Quantitative changes in DNA, RNA and protein during prenatal and postnatal growth in the rat. Develop. Biol. 12: 451 (1965).

10. Winick, M. and Noble, A.: Quantitative changes in ribonucleic acids and protein during normal growth of rat placenta. Nature (Lond.) 212: 5057 34 (1966).

11. This work has been supported by New York City Health Research Council Grant U1769 and the Nutrition Foundation Grant No. 357.

12. Requests for reprints should be addressed to: $\mathrm{Mr}$ RON WINIck, M.D., Department of Pediatrics, The New York Hospital, 525 E. 68th Street, New York, N.Y. 10021 (USA). 